ఠ

\title{
Metastatic leiomyosarcoma presenting as a lung mass with left atrial extension: case report and anesthetic management
}

This article was published in the following Dove Press journal:

Therapeutics and Clinical Risk Management

\author{
Yinyin Qu' \\ Qing Zheng' \\ Cheng $\mathrm{Ni}^{\prime}$ \\ Zhongqi Cui ${ }^{2}$ \\ Xiangyang Guo' \\ 'Department of Anesthesiology, \\ ${ }^{2}$ Department of Cardiac Surgery, \\ Peking University Third Hospital, \\ Beijing, People's Republic of China
}

Correspondence: Cheng Ni; Qing Zheng Department of Anesthesiology, Peking University Third Hospital, 49 North Garden Rd., Haidian District, Beijing I00191, People's Republic of China

Tel +86 I0 82267270

Fax +86 I0 82267276

Email nicheng@hsc.pku.edu.cn; zhengqing1970@live.cn

\begin{abstract}
Introduction: Lung metastasis of leiomyosarcoma that protrudes into the left atrium is an extremely rare condition. Severe complications may occur that prominently increase the mortality during the perioperative period. Currently, the anesthetic management reports are limited and there is no generally acknowledged algorithm available.

Case presentation: A 67-year-old man presented with cough and dyspnea for 10 days. Workup revealed bilateral pulmonary effusion. Transthoracic echocardiography showed a large mass in the left atrium. Urgent surgical resection under cardiopulmonary bypass was performed. We focused on oxygenation improvement and cardiac function management by applying protective ventilation with low positive end expiratory pressure, low dose inotropic agents, and other methods to maintain stable homeostasis. Results of biopsy established a diagnosis of metastatic leiomyosarcoma.

Conclusion: We reported a case of metastatic leiomyosarcoma presenting as a lung mass with left atrial extension and anesthetic management during surgical resection. Treating acute heart failure and refractory hypoxemia was the key focus perioperatively.
\end{abstract}

Keywords: leiomyosarcoma, metastatic, anesthesia, acute heart failure, hypoxemia

\section{Introduction}

Superficial leiomyosarcoma is a rare malignant tumor with an overall incidence of $0.04 \%$ among all cancers. ${ }^{1}$ Lung metastasis of leiomyosarcoma that protrudes into the left atrium is extremely rare. Severe complications such as widespread emboli and circulation impairment may occur due to outflow obstruction. Anesthesia management of a patient under such circumstances is challenging and rarely reported, because the tumor may result in respiratory compromise and circulation collapse. In the present case, we described a patient who was preoperatively diagnosed as left atrial myxoma. He was scheduled for emergent left atrial mass resection under general anesthesia with cardiopulmonary bypass (CPB), and histopathological examination revealed features consistent with leiomyosarcoma. During the surgical procedure, the patient presented refractory hypoxemia, increased pulmonary arterial pressure and severely compromised cardiac function. Thus, we report the case focusing on the perioperative management during surgical resection of the tumor, including oxygenation improvement and circulation stabilization.

\section{Case presentation}

A 67-year-old man with a height of $183 \mathrm{~cm}$ and a weight of $105 \mathrm{~kg}$ was admitted for urgent resection of a left atrial mass. He presented with progressive heart failure that 

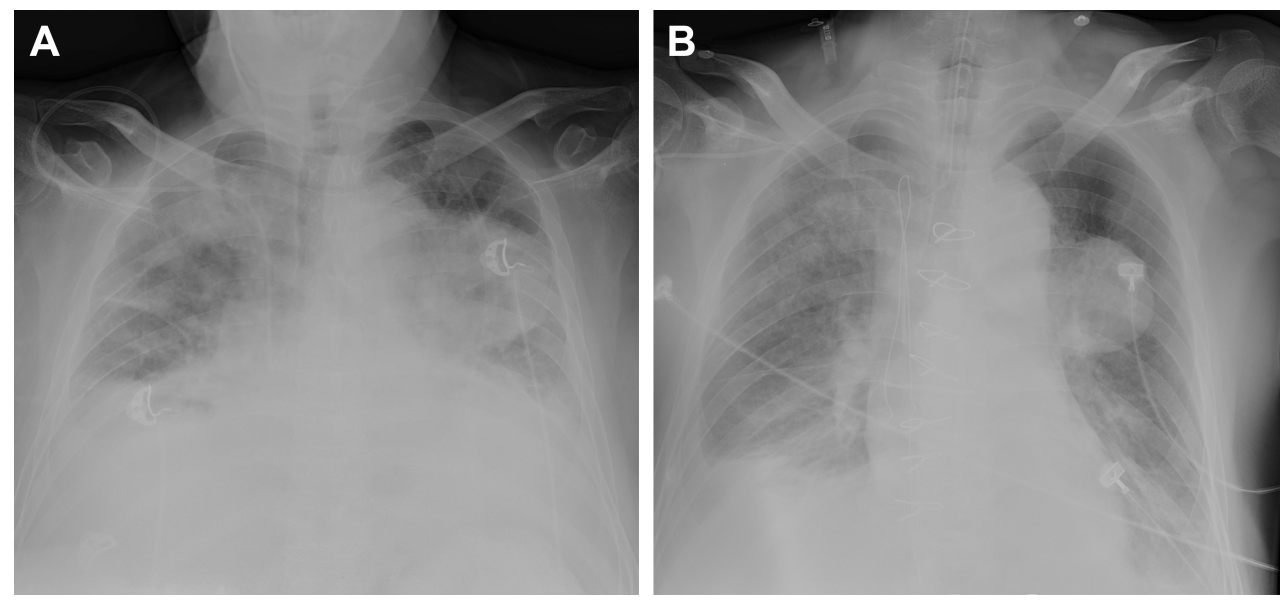

Figure I Preoperative and postoperative chest X-ray of the patient.

Notes: (A) Posterior-anterior chest X-ray preoperatively showing pulmonary edema and a mass in the left lung. (B) Chest X-ray $3 \mathrm{~h}$ postoperatively showing pulmonary edema was relieved, and the lung mass became distinct.

could not be alleviated by inotropic or vasodilating drugs and had been coughing for 10 days. The symptoms had aggravated, and he had been unable to keep supine position for the last 3 days. He denied any previous heart disease. He had a history of right elbow leiomyosarcoma and underwent resection surgery 1 year previously.

On physical examination, the patient showed orthopnea and a compulsive position of slight left tilting. Wet rales could be heard on bilateral lung base. III/6 diastolic rumble was heard through the apex of the heart, which attenuated with upright position.

The preoperative laboratory data were within normal limits, except for NT-proBNP 1,190 pg/L. The electrocardiogram showed sinus tachycardia and minor ST segment change. Chest $\mathrm{X}$-ray demonstrated prominent pulmonary patches infiltration, suggesting possible pulmonary edema. A mass was noted on the left lung. Combined with the malignancy history of the patient, pulmonary metastasis was suspected, whereas primary pulmonary tumor could not be ruled out (Figure 1A). Transthoracic echocardiography (TTE) showed a mobile isoechoic to hyperechoic lumpy mass $(54 \times 27 \mathrm{~mm}$, Figure 2$)$ and medium pulmonary hypertension $(67 \mathrm{mmHg})$, and the ejection fraction of the left ventricle was $65 \%$.

According to symptoms of left-sided heart failure, signs of mitral stenosis, and ultrasound imaging, myxoma was highly suspected. The TTE image indicated that the mass originated from the posterior wall of the left atrium (the typical myxoma is pedunculated with a stalk commonly attached to the fossa ovalis of interatrial septum ${ }^{6}$ ). Differential diagnoses included idiopathic pulmonary arterial hypertension (IPAH), pulmonary embolism, pulmonary tumor thrombotic microangiopathy, and acute respiratory distress syndrome
(ARDS). There is not enough evidence to support the differential diagnoses above.

In the operating room, monitors consisting of noninvasive blood pressure (NIBP), five-lead electrocardiogram, and pulse oximetry $\left(\mathrm{SpO}_{2}\right)$ were applied. Radial arterial line and central venous catheter in the right subclavian vein were inserted, and then, arterial blood pressure (ABP) and central venous pressure (CVP) were monitored. Vital signs of the patient were basically stable with continuous intravenous nitroglycerin at the rate of $0.5 \mu \mathrm{g} / \mathrm{kg} / \mathrm{min}$. ABP was $121 / 82 \mathrm{mmHg}$, and CVP was $8 \mathrm{cmH}_{2} \mathrm{O}$, while heart rate (HR) was $111 \mathrm{bpm}$. His $\mathrm{SpO}_{2}$ was $92 \%-93 \%$ (fraction of inspired oxygen $\left[\mathrm{FiO}_{2}\right] 60 \%$ ). Airway assessment indicated several risk factors: obesity, short neck, impaired neck mobility, and Mallampati classification grade III. When the patient was awake with topical anesthesia of the tongue and pharynx, partial glottis was observed (Cormack-Lehane 2b) with direct laryngoscope. Thus, we

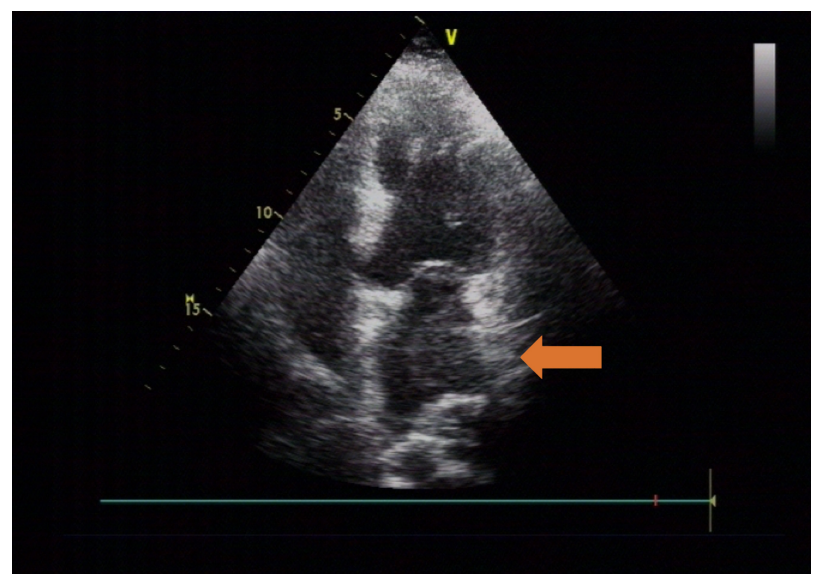

Figure 2 Hyperechoic lumpy mass detected on transthoracic echocardiography. Note: Apical four chamber view showing the mass in the left atrium (orange arrow). 
Table I Arterial blood gas analysis and ACT during surgery

\begin{tabular}{llllll}
\hline Time point & $\begin{array}{l}\text { After } \\
\text { intubation }\end{array}$ & $\begin{array}{l}\text { Before } \\
\text { CPB }\end{array}$ & $\begin{array}{l}\text { CPB } \\
\mathbf{4 0} \text { min }\end{array}$ & $\begin{array}{l}\text { CPB } \\
\mathbf{8} \text { min }\end{array}$ & $\begin{array}{l}\text { After } \\
\text { CPB }\end{array}$ \\
\hline $\mathrm{PH}$ & 7.39 & 7.43 & 7.50 & 7.55 & 7.42 \\
$\mathrm{PaO}_{2}(\mathrm{mmHg})$ & 57 & 48 & 313 & 453 & 68 \\
$\mathrm{PaCO}_{2}(\mathrm{mmHg})$ & 49 & 44 & 36 & 35 & 41 \\
$\mathrm{BE}(\mathrm{mEg} / \mathrm{L})$ & 3.2 & 3.9 & 3.9 & 6.8 & 0.9 \\
$\mathrm{Hb}(\mathrm{g} / \mathrm{L})$ & 103 & 87 & 88 & 100 & 89 \\
ACT $(\mathrm{s})$ & 118 & 489 & 496 & 592 & 134 \\
\hline
\end{tabular}

Abbreviations: $A C T$, activated clotting time; $B E$, base excess; $C P B$, cardiopulmonary bypass; $\mathrm{Hb}$, hemoglobin; $\mathrm{PaCO}_{2}$, partial pressure of carbon dioxide in artery; $\mathrm{PaO}_{2}$, partial pressure of oxygen in artery.

considered the mask ventilation was feasible and anesthesia induction was conducted. After preoxygenation with oxygen (10 L/min) for $5 \mathrm{~min}$ via a face mask, general anesthesia was induced using Renfushufen ${ }^{\circledR}$ (sufentanil) $1 \mu \mathrm{g} / \mathrm{kg}$, etomidate $0.15 \mathrm{mg} / \mathrm{kg}$, and rocuronium $0.6 \mathrm{mg} / \mathrm{kg}$ (ideal body weight). Orotracheal intubation was performed with video laryngoscope when the patient was kept in the $60^{\circ}$ Semi-Fowler's position to avoid circulation collapse. Because mitral valve occlusion by left atrial mass may result in low cardiac output. Volume-controlled ventilation was applied (tidal volume of $8 \mathrm{~mL} / \mathrm{kg}$, frequency adjusted to maintain partial pressure of carbon dioxide in artery $\left[\mathrm{PaCO}_{2}\right]$ between 35 and $45 \mathrm{mmHg}$, and inspiratory/expiratory (I/E) ratio 1:2). The airway peak pressure was $28-30 \mathrm{cmH}_{2} \mathrm{O}$. After intubation, the $\mathrm{SpO}_{2}$ was only $90 \%-93 \%\left(\mathrm{FiO}_{2} 60 \%\right)$. Arterial gas analysis during surgery is shown in Table 1. Abnormalities of airway, breathing, drug effects, and equipment were not found; thus, pulmonary edema was considered as the main reason for hypoxia. $\mathrm{FiO}_{2}$ $100 \%$ was provided to improve oxygenation. Respiratory rate was increased to enhance minute ventilation volume. Positive end expiratory pressure (PEEP) was supplied to prevent alveoli from collapsing to improve pulmonary compliance and gas exchange and to decrease extravascular lung water. ${ }^{7}$ PEEP was titrated to $6 \mathrm{cmH}_{2} \mathrm{O}$ to avoid high PEEP-related compromise preload. Then, $\mathrm{SpO}_{2}$ improved to $94 \%-95 \%$. Vital signs and ventilation parameters during surgery are shown in Table 2. Anesthesia was maintained with sufentanil $20 \mu \mathrm{g} / \mathrm{h}$ and sevoflurane $2 \%-2.5 \%$ (concentration of sevoflurane was adjusted according to the patient's increased $\left.\operatorname{age}^{8}\right)$, and rocuronium was given intermittently.

After median sternotomy, $400 \mathrm{U} / \mathrm{kg}$ heparin was administered. Arterial cannulation was performed via ascending aorta. Venous cannulation was inserted via the right atrial appendage into the superior and inferior vena cava. After CPB was established, oxygenation of the patient improved significantly with the $\mathrm{SpO}_{2}$ improved to $99 \%-100 \%$. The patient was kept anesthetized with midazolam $0.1 \mathrm{mg} / \mathrm{kg} / \mathrm{h}$, sufentanil $0.15 \mu \mathrm{g} / \mathrm{kg} / \mathrm{h}$, and rocuronium $0.15 \mathrm{mg} / \mathrm{kg} / \mathrm{h}$ intravenously under hypothermic $\mathrm{CPB}$, and nasopharyngeal and rectal temperature were maintained at $25^{\circ} \mathrm{C}$ and $28^{\circ} \mathrm{C}$, respectively. Activated clotting time (ACT) was performed intermittently, and the results are shown in Table 1.

Under direct view, the mass was large and occupied nearly the entire left atrium. The right atrium and atrial septum were incised, and the mass was found attached by a stalk to the opening of the left superior pulmonary vein. The mass in the left atrium was totally resected, and was $15 \times 2 \mathrm{~cm}$. The tumor in the left superior pulmonary vein could not be completely resected, and palliative resection of the tumor around the opening of the left superior pulmonary vein was performed to ease tumor-related symptoms. As a result, preload was improved while pulmonary hypertension remained a problem. After rewarming and deairing of the heart, the aortic cross-clamp was removed. The heart came back into sinus rhythm with $20 \mathrm{~J}$ intracardiac defibrillation, and then, the CPB was discontinued gradually. Weaning was facilitated with norepinephrine $0.05 \mu \mathrm{g} / \mathrm{kg} / \mathrm{min}$ and dopamine $5 \mu \mathrm{g} / \mathrm{kg} / \mathrm{min}$ to achieve goal mean arterial BP $>65 \mathrm{mmHg}$. Nitroglycerin $0.5-0.8 \mu \mathrm{g} / \mathrm{kg} / \mathrm{min}$ was used to decrease systemic vascular resistance. A total of $800 \mathrm{~mL}$ of packed red blood cells were gradually infused to increase preload. Vital signs showed an ABP of $110 / 70 \mathrm{mmHg}$, an HR of $110 \mathrm{bpm}$, a CVP of $12 \mathrm{cmH}_{2} \mathrm{O}$, and an $\mathrm{SpO}_{2}$ of $93 \%-95 \%$. Heparin was neutralized with protamine ( $1 \mathrm{mg} / 100 \mathrm{U}$ heparin). The total CPB time was $100 \mathrm{~min}$, and the aortic occlusion time was $85 \mathrm{~min}$. The overall fluid balance during $\mathrm{CPB}$ was $-2,700 \mathrm{~mL}$. The estimated blood

Table 2 Vital signs and ventilation parameters during surgery

\begin{tabular}{lllllll}
\hline Time point & Preoperative & $\begin{array}{l}\text { After } \\
\text { intubation }\end{array}$ & Adjustment & $\begin{array}{l}\text { After } \\
\text { CPB }\end{array}$ & Extubation & Recovery \\
\hline $\mathrm{HR}(\mathrm{bpm})$ & $\mathrm{III}$ & 120 & 125 & 110 & 110 & 72 \\
$\mathrm{ABP}(\mathrm{mmHg})$ & $12 \mathrm{I} / 82$ & $110 / 58$ & $120 / 69$ & $110 / 70$ & $110 / 71$ & $121 / 72$ \\
$\mathrm{SpO}(\%)$ & 92 & 90 & 94 & 93 & 95 & 95 \\
Airway peak pressure $\left(\mathrm{cmH}_{2} \mathrm{O}\right)$ & - & 28 & 24 & 25 & - & - \\
PEEP $\left(\mathrm{cmH}_{2} \mathrm{O}\right)$ & - & - & 6 & 6 & - & - \\
\hline
\end{tabular}

Abbreviations: $A B P$, arterial blood pressure; $C P B$, cardiopulmonary bypass; $\mathrm{HR}$, heart rate; $\mathrm{PEEP}$, positive end expiratory pressure; $\mathrm{SpO}_{2}$, pulse oximetry. 
loss was $800 \mathrm{~mL}$. Arterial blood gas analysis after CPB discontinuation is also showed in Table 1.

After CPB, the partial pressure of oxygen in artery $\left(\mathrm{PaO}_{2}\right)$ was $68 \mathrm{mmHg}$ with $\mathrm{FiO}_{2} 100 \%$ and PEEP $6 \mathrm{cmH}_{2} \mathrm{O}$ and was increased from that before tumor resection $(48 \mathrm{mmHg})$. After excluding bronchospasm and acute lung injury, we assumed that this was due to unrelieved cardiogenic pulmonary edema and pulmonary hypertension, as well as residual tumor in the pulmonary vessels. Inotropic agents including epinephrine $0.05 \mu \mathrm{g} / \mathrm{kg} / \mathrm{min}$, dopamine $5 \mu \mathrm{g} / \mathrm{kg} / \mathrm{min}$, and nitroglycerin $0.5-0.8 \mu \mathrm{g} / \mathrm{kg} / \mathrm{min}$ were continuously used to improve cardiac output and facilitate stable hemodynamics, so as to alleviate pulmonary edema. Hyperventilation was applied to decrease $\mathrm{PaCO}_{2}$ and prevent acidosis. Hypoxia pulmonary vasoconstriction may have been partially inhibited, and pulmonary artery systolic pressure was decreased from 67 to $<35 \mathrm{mmHg}$ (postoperative TTE). The patient was transferred to the intensive care unit with $\mathrm{BP}$ 110/71 mmHg, $\mathrm{HR} 110 \mathrm{bpm}$, and $\mathrm{SpO}_{2} 95 \%$ during admission. Oxygenation was improved compared to the level before left atrial tumor resection ( $91 \mathrm{vs} 48 \mathrm{mmHg}$ ), and HR was decreased (103 vs $111 \mathrm{bpm}$ ), indicating that pulmonary edema was partially relieved. Increasing $\mathrm{FiO}_{2}$, decreasing $\mathrm{O}_{2}$ consumption, and optimizing acid-base balance and hemoglobin, together with protective ventilation, were provided and resulted in oxygenation improvement. Vasoactive medications and mechanical ventilation were gradually weaned, and vital signs remained stable. Chest X-ray performed $3 \mathrm{~h}$ postoperatively revealed significantly relieved pulmonary edema (Figure 1B). The patient was extubated on postoperative day 4 while he was conscious, and the vital signs showed BP $121 / 72 \mathrm{mmHg}$, HR 72 bpm, and $\mathrm{SpO}_{2} 95 \%-97 \%$ with $\mathrm{FiO}_{2} 85 \%$. He was discharged 10 days after the surgery with symptoms ameliorated and $\mathrm{SpO}_{2} 97 \%$ with $\mathrm{FiO}_{2} 21 \%$. Histopathological examination of the resected lesion revealed features consistent with leiomyosarcoma. Further management of the lung metastasis of leiomyosarcoma and possible radiation therapy are needed. ${ }^{9}$ Some authors suggest that multimodal therapy (surgical resection, radiation treatment, and chemotherapy) may result in reasonable survival improvement for patients..$^{10}$ Isambert et $\mathrm{a}^{11}$ reported a mean survival of 18.2 months after incomplete resection and 11.2 months in nonresected patients. In our case, the patient received palliative treatment after surgery and died of tumor-related cardiopulmonary failure 6 months later. The timeline of history, interventions, and outcomes are summarized in Figure 3.

\section{Consent for publication}

Written informed consent was obtained from the patient's next of kin for publication of this case report.

\section{Discussion}

Superficial leiomyosarcoma, a rare malignant lesion, constitutes $4.0 \%-6.5 \%$ of all soft tissue sarcomas, ${ }^{1}$ including cutaneous and subcutaneous leiomyosarcoma. Subcutaneous leiomyosarcoma arises from vascular structures in the subcutaneous cellular tissue and has an increased risk of recurrence and metastasis. ${ }^{12}$ Aneiros-Fernandez et a ${ }^{12}$ concluded that subcutaneous subtype is likely to have a $18.28 \%-50 \%$ chance of recurrence and a $27.27 \%-66.66 \%$ chance to metastasize. The mortality rate of subcutaneous leiomyosarcoma is $9.09 \%-70 \%{ }^{12}$ Pulmonary metastases may appear simultaneously with the diagnosis. Lung metastasis of subcutaneous leiomyosarcoma that protrudes in to left atrium is extremely rare. In fact, leiomyosarcoma accounts for $<1 \%$ of tumors that metastasize to the heart. ${ }^{2}$ Several cases of lung metastasis from leiomyosarcoma with atrial extension have been reported; ${ }^{2-5}$ two patients underwent surgical treatment and others received palliative therapy.

In our case, according to the patient's past medical history, perioperative symptoms, clinical and experimental examinations, and histological findings, we considered the possibility of him having atrial extension of lung metastasis from leiomyosarcoma. The pathophysiology changes of this case simulated pathophysiology of lung cancer invading the left atrium. Metastatic tumor in the pulmonary vein and left atrium may cause congestive heart failure due to blood flow obstruction and left ventricle filling defect. Passive backward transmission of the elevated atrial pressure led to insufficient preload of the left ventricle, increased pulmonary hydrostatic pressure, and then pulmonary edema. Giant myxoma shares similar mechanisms, which made it difficult to identify specific etiology preoperatively.

Anesthetic management remains a great challenge due to compromised cardiac function, increased pulmonary arterial pressure, pulmonary effusion, and refractory hypoxemia. ${ }^{13}$ Hypoxemia was a constant problem in our case throughout the perioperative period. The reasons could be the left atrium pulmonary vein inducing left atrial pressure elevation and pulmonary hypertension, ${ }^{13}$ and related pulmonary edema. ${ }^{5}$ During the process, PEEP could be used to improve oxygenation and pulmonary compliance. The optimal PEEP to balance oxygenation, compliance, and ventilation-induced lung injury remains to be investigated. Increased PEEP in ARDS could protect alveoli and improve arterial oxygenation but reduces cardiac output and impairs tissue oxygen delivery. ${ }^{14}$ Ladha et al ${ }^{15}$ suggested a PEEP of $5 \mathrm{cmH}_{2} \mathrm{O}$ and a plateau pressure of $\leq 16 \mathrm{cmH}_{2} \mathrm{O}$ as protective mechanical ventilator settings during operation. In our case, relatively low PEEP level and $100 \% \mathrm{FiO}_{2}$ were applied after intubation 


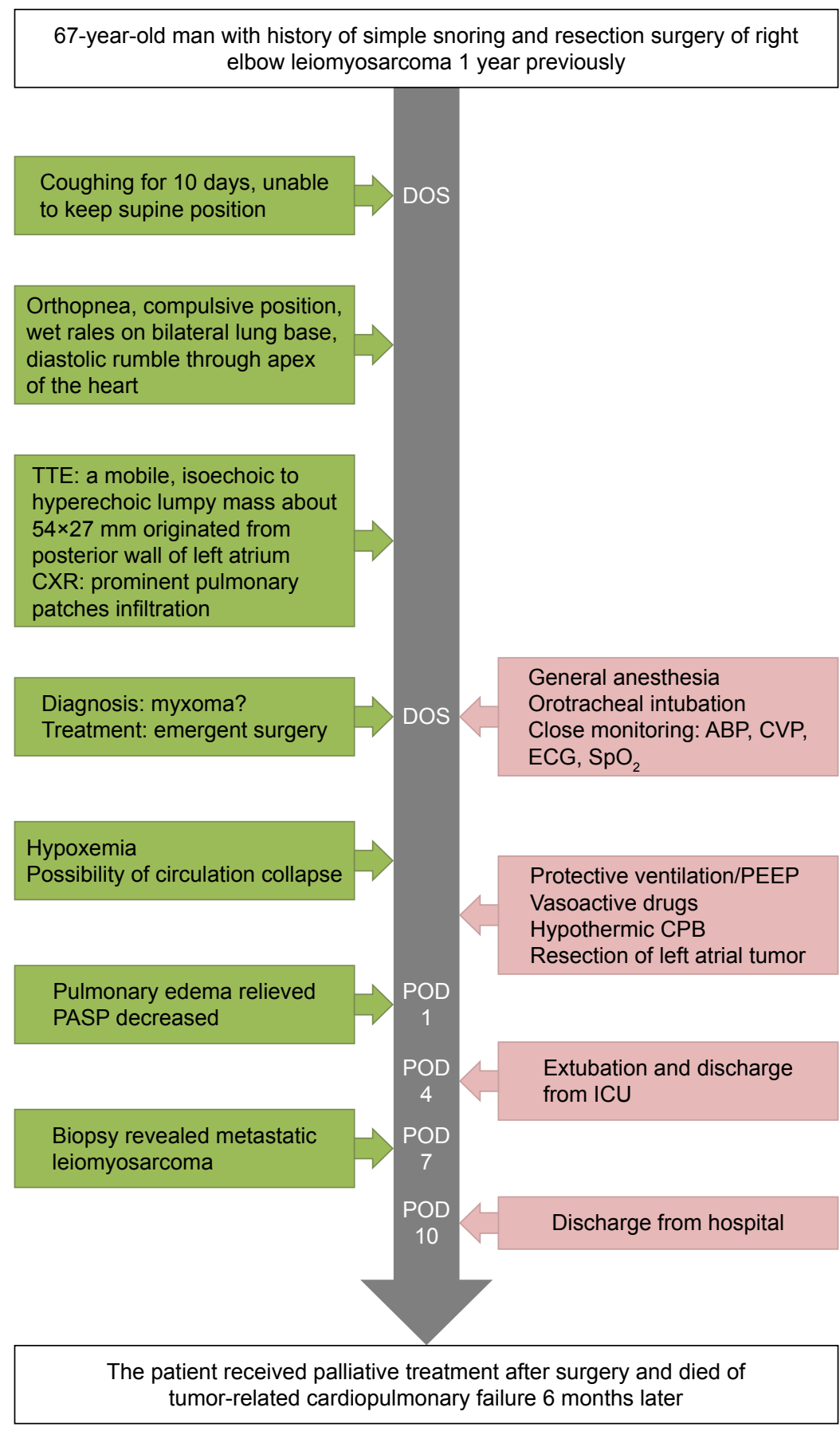

Figure 3 Timeline of interventions and outcomes.

Abbreviations: ABP, arterial blood pressure; CPB, cardiopulmonary bypass; CVP, central venous pressure; CXR, chest X-ray; DOS, day of surgery; ECG, electrocardiogram; ICU, intensive care unit; PASP, pulmonary arterial systolic pressure; PEEP, positive end expiratory pressure; POD, postoperative day; TTE, transthoracic echocardiography; $\mathrm{SpO}_{2}$, pulse oximetry.

to increase oxygenation and minimize the effects on cardiac output. Acute lung injury (ALI) could not be fully excluded, and protective ventilation has been reported to associate with a lower rate of ALI, ${ }^{16}$ so protective ventilation including low tidal volume of $6-8 \mathrm{~mL} / \mathrm{kg}$ with PEEP and recruitment maneuver was applied during operation. Packed red blood cells were transfused to maintain hematocrit $>0.25$ and increase oxygen carrying capacity. During anesthesia induction, the patient was kept in a fixed position to avoid an occlusion effect of the tumor and following hemodynamic collapse, and a stable intraoperative hemodynamic status was maintained to improve oxygenation.

It is important to prevent systemic thromboembolic events during resection of the tumor. Dias et a ${ }^{17}$ reported that thromboembolic events mainly occurred in the central nervous system $(10.2 \%)$, coronary arteries $(4.8 \%)$, and lower 
limbs (4.3\%) and the histological type of tumors correlates with embolic events and mortality. Resection of cardiac tumor has been suggested to prevent emboli and sudden death. ${ }^{18}$ Left pulmonary vein atrial inflow patch closure has been reported as a preventive and less invasive measure to reduce thromboembolic risk. ${ }^{19}$ In our case, palliative resection of the tumor around the opening of the left superior pulmonary vein was performed instead of left pulmonary vein patch closure to increase preload and ameliorate symptoms of left heart failure.

In some cases, partial or lobar pneumonectomy together with atrial mass resection can be performed depending on the degree of cardiac involvement and the stage of the tumor. ${ }^{20}$ Besides, complete resection of the atrial tumor is impossible in some cases and the mortality rate is high. ${ }^{21}$ In our case, pneumonectomy was not conducted simultaneously because of advanced pulmonary edema, unclear boundary of pulmonary infiltration, risks of hemorrhage, and possible patient intolerance. Considering the patient's malignancy history, and suspicious mass indicated by chest X-ray, a preoperative CT or MRI scan was recommended. They were not conducted because change of the patient's position may have resulted in sudden mitral orifice obstruction, and preoperative TTE was conducted instead. Because the cardiac tumor resulted in unstable hemodynamics and the diagnosis was uncertain, transesophageal echocardiography (TEE) and pulmonary artery catheter were not used during the case. However, TEE has potential advantages and is recommended by the American Society of Echocardiography. ${ }^{22}$ It could be the best way to assess the left atrium volume, transmitral flow, and the hemodynamic effects of surgical resection, and we recommend the use of TEE without contraindications.

\section{Conclusion}

Lung metastasis with left atrial extension of leiomyosarcoma is a rare and challenging scenario, during which refractory hypoxemia, pulmonary edema, severe compromised cardiac function, and possible embolic events are main difficulties for anesthetic management. In our case, we focused on oxygenation and cardiac function management through applying protective ventilation with low PEEP, increase in $\mathrm{FiO}_{2}$, decrease in oxygen consumption, optimization of acid-base balance and hemoglobin, low dose of inotropic agents, as well as surgical resection of the tumor.

\section{Data sharing statement}

All data and materials described in the article will be freely available to any scientist wishing to use them for noncommercial purposes. Raw data are not available, as all are in the patient's electronic medical record.

\section{Acknowledgment}

This study was supported by the National Natural Science Foundation of China (No 81400869) and Key Research Foundation from Peking University Third Hospital.

\section{Author contributions}

All authors contributed toward data analysis, drafting and critically revising the paper, and agree to be accountable for all aspects of the work.

\section{Disclosure}

The authors report no conflicts of interest in this work.

\section{References}

1. Wascher RA, Lee MY. Recurrent cutaneous leiomyosarcoma. Cancer. 1992;70(2):490-492.

2. Lopez FF, Mangi A, Mylonakis E, Chen JL, Schiffman FJ. Atrial fibrillation and tumor emboli as manifestations of metastatic leiomyosarcoma to the heart and lung. Heart Lung. 2000;29(1):47-49.

3. Collins NJ, Barlow MA, Woodford PA, Hayes PC. Intracardiac extension of metastatic pulmonary leiomyosarcoma. Heart Lung Circ. 2005; 14(2):121-122.

4. Khan A, Ahmad M, Omran A, Arifi AA. Pulmonary metastatic leiomyosarcoma invading the left atrium through the pulmonary veins. J Saudi Heart Assoc. 2012;24(3):213-214.

5. Peng YJ, Hueng GG, Lee HS. Acute heart failure as manifestation of metastatic uterine leiomyosarcoma to the heart and lung. Heart Lung. 2004;33(1):46-49.

6. Burke A, Tavora F. The 2015 WHO classification of tumors of the heart and pericardium. $J$ Thorac Oncol. 2016;11(4):441-452.

7. Wiesen J, Ornstein M, Tonelli AR, Menon V, Ashton RW. State of the evidence: mechanical ventilation with PEEP in patients with cardiogenic shock. Heart. 2013;99(24):1812-1817.

8. Nickalls RW, Mapleson WW. Age-related iso-MAC charts for isoflurane, sevoflurane and desflurane in man. Br J Anaesth. 2003;91(2):170-174.

9. Salemis NS. Recurrent subcutaneous trunk leiomyosarcoma: management and review of the literature. J Nat Sci Biol Med. 2013;4(1): 238-242.

10. Bakaeen FG, Jaroszewski DE, Rice DC, et al. Outcomes after surgical resection of cardiac sarcoma in the multimodality treatment era. J Thorac Cardiovasc Surg. 2009;137(6):1454-1460.

11. Isambert N, Ray-Coquard I, Italiano A, et al. Primary cardiac sarcomas: a retrospective study of the French Sarcoma Group. Eur J Cancer. 2014; 50(1):128-136.

12. Aneiros-Fernandez J, Antonio Retamero J, Husein-Elahmed H, Ovalle F, Aneiros-Cachaza J. Primary cutaneous and subcutaneous leiomyosarcomas: evolution and prognostic factors. Eur J Dermatol. 2016;26(1):9-12.

13. Porteous MK, Fritz JS. Hypoxemia in a patient with pulmonary arterial hypertension: getting to the heart of the matter. Ann Am Thorac Soc. 2014; 11(5):836-840.

14. Chikhani M, Das A, Haque M, Wang W, Bates DG, Hardman JG. High PEEP in acute respiratory distress syndrome: quantitative evaluation between improved arterial oxygenation and decreased oxygen delivery. Br J Anaesth. 2016;117(5):650-658.

15. Ladha K, Vidal Melo MF, McLean DJ, et al. Intraoperative protective mechanical ventilation and risk of postoperative respiratory complications: hospital based registry study. BMJ. 2015;351:h3646. 
16. Neto AS, Hemmes SNT, Barbas CSV, et al. Incidence of mortality and morbidity related to postoperative lung injury in patients who have undergone abdominal or thoracic surgery: a systematic review and meta-analysis. Lancet Respir Med. 2014;2(12):1007-1015.

17. Dias RR, Fernandes F, Ramires FJ, Mady C, Albuquerque CP, Jatene FB. Mortality and embolic potential of cardiac tumors. Arq Bras Cardiol. 2014;103(1):13-18.

18. Cianciulli TF, Saccheri MC, Lax JA, et al. Left ventricular thrombus mimicking primary cardiac tumor in a patient with primary antiphospholipid syndrome and recurrent systemic embolism. Cardiol J. 2009; 16(6):560-563.

19. Santise G, Raffa GM, Pilato M. Surgical treatment of systemic embolization by cardiac metastasis of lung cancer. Asian Cardiovasc Thorac Ann. 2014;22(9):1103-1105.
20. Shimizu J, Ikeda C, Arano Y, et al. Advanced lung cancer invading the left atrium, treated with pneumonectomy combined with left atrium resection under cardiopulmonary bypass. Ann Thorac Cardiovasc Surg. 2010;16(4):286-290.

21. Andrushchuk U, Ostrovsky Y, Zharkov V, et al. Surgery for massive malignant tumors of the left atrium - one center's experience. Kardiochir Torakochirurgia Pol. 2016;13(3):229-235.

22. Saric M, Armour AC, Arnaout MS, et al. Guidelines for the Use of Echocardiography in the Evaluation of a Cardiac Source of Embolism. J Am Soc Echocardiogr. 2016;29(1):1-42.

\section{Publish your work in this journal}

Therapeutics and Clinical Risk Management is an international, peerreviewed journal of clinical therapeutics and risk management, focusing on concise rapid reporting of clinical studies in all therapeutic areas outcomes, safety, and programs for the effective, safe, and sustained use of medicines. This journal is indexed on PubMed Central, CAS,
EMBase, Scopus and the Elsevier Bibliographic databases. The manuscript management system is completely online and includes a very quick and fair peer-review system, which is all easy to use. Visit http://www.dovepress.com/testimonials.php to read real quotes from published authors.

Submit your manuscript here: http://www.dovepress.com/therapeutics-and-clinical-risk-management-journal 